\title{
Estratégias de gestão dos municípios em cenário de crise socioeconômica
}

\author{
Management strategies of municipalities in a scenario of \\ socioeconomic crisis
}

\author{
JEFFERSON MARIANO ${ }^{\mathrm{a}}$ \\ LÍVIA INGLESIS BARCELLOS ${ }^{b}$
}
a Doutor em Desenvolvimento Econômico. Professor na Faculdade Cásper Líbero e Analista do Instituto Brasileiro de Geografia e Estatística (IBGE).
E-mail: jefferson.mariano@ibge.gov.br
b Bacharel em Comunicação Social pela Pontifícia Universidade Católica de São Paulo (PUC-SP).
E-mail: iviaib@outlook.com

\begin{abstract}
Este trabalho tem por objetivo realizar uma análise das estratégias de gestão adotadas pelos municípios do estado de São Paulo entre 2010 e 2015, com ênfase para as ações relativas aos incentivos para geração de trabalho e rendimento. A economia brasileira passou por uma transição de taxas elevadas de crescimento para um período de forte retração na atividade econômica. Em função disso, instrumentos de política econômica foram utilizados com vistas à retomada do crescimento. $\mathrm{O}$ trabalho pretende demonstrar que no nível territorial municipal também foram realizadas ações no sentido de retomar o ciclo de crescimento da economia, especialmente em relação ao emprego. Para a realização deste trabalho, foram explorados dados disponibilizados pela Pesquisa do Cadastro Central de Empresas do Instituto Brasileiro de Geografia e Estatística (IBGE). Trata-se de um levantamento que fornece informações sobre pessoas ocupadas e salários, e outras remunerações de empresas e unidades locais formalmente constituídas, registradas no Cadastro Nacional de Pessoa Jurídica CNPJ. Outra fonte utilizada para este trabalho foi a Pesquisa Informações Básicas Municipais, também elaborada pelo IBGE. A revisão da literatura apresenta como referência os trabalhos utilizados pela Fundação Getúlio Vargas, Instituto de Pesquisas Econômicas Aplicadas (IPEA) e os estudos de Wilson Cano, do Instituto de Economia da Unicamp.
\end{abstract}

Palavras-chave: Federalismo, poder local, gestão pública.

This work aims to carry out an analysis of management strategies adopted by the municipalities of São Paulo State between 2010 and 2015, with emphasis on the actions related to incentives to generate jobs and income. The Brazilian economy has undergone a transition from high growth rates to a strong period of retraction in economic activity. As a result, economic policy instruments were used in order to return to growth. The work aims to demonstrate that the municipal territorial level were also carried out actions to resume the growth cycle of the economy, especially in relation to employment. To carry out the work in question, data released by the Research Center of Companies Register of the Brazilian Institute of Geography and Statistics (IBGE) was used. This is a survey that provides information on wages and occupied people, and other compensation of enterprises and local units formally constituted, registered in the National Registry of Legal Entities GNPJ. Another source used for this task was to search Basic Municipal Information, also prepared by the IBGE. The literature presents as a reference work used by the Getulio Vargas Foundation, Institute of Applied Economic Research (IPEA) and the studies of Wilson Cano, the Economics Institute of Unicamp.

Keywords: Federalism, local authorities, public administration. 


\section{A RELAÇÃO ENTRE OS ENTES FEDERATIVOS}

A descentralização da capacidade de gestão, com maior autonomia para a atuação dos municípios, foi um processo que se intensificou a partir do início dos anos 1990, como resultado das alterações introduzidas pela Constituição de 1988.

Antes desse período, especialmente ao longo da ditadura militar (1964-1985), os mecanismos constitucionais existentes não estavam suficientemente claros no tocante à redistribuição dos recursos, extremamente centralizados no âmbito do governo federal, e, paralelamente, as transferências pautavam-se por aspectos de natureza discricionária.

Uma das características do regime de arbítrio era a excessiva centralização do processo decisório. No âmbito das finanças públicas, houve o estabelecimento de uma estrutura profundamente amparada em transferências, que segundo Tavares (1986), não estava fortemente institucionalizada.

Desse modo, transferências realizadas para estados e municípios estavam pautadas na agenda política e na necessidade de apoio institucional, principalmente quando o regime passou a enfrentar problemas relacionados à legitimação política. Apesar da forte centralização do processo decisório político no nível federal, em razão do "milagre econômico", as tensões nos estados e municípios foram minimizadas.

As pressões por democratização e descentralização ocorreram no fim dos anos 1970, devido ao agravamento da crise econômica, ao lado da emergência do novo sindicalismo, com seus desdobramentos sobre os demais movimentos sociais.

Assim, na fase de elaboração da Constituição de 1988, colocava-se na agenda política brasileira a necessidade de um processo de descentralização das receitas, em benefício do poder local e de institucionalização de transferências intergovernamentais.

A partir da Constituição de 1988, ocorreu de fato uma redução da participação da União na receita tributária total e um aumento em favor dos estados e municípios.

Uma reação desse processo por parte da União foi a intensificação de contribuições de natureza social ou econômica. Ressalta-se que as contribuições sociais foram mecanismos criados, principalmente a partir dos anos 1970, que permitiam ao governo programar políticas sociais a despeito de restrições orçamentárias e sem depender diretamente do aumento da receita de impostos.
Outro resultado do processo de aumento da participação dos recursos orçamentários por parte das esferas locais de poder foi a possibilidade de constituição de novos municípios, com a consequente criação de 1000 unidades, após 1988. No estado de São Paulo, havia, em 1990, 575 prefeituras, em 1990, que, em 2002, passaram a ser 645 . A criação, incorporação e desmembramento de municípios, que era uma prerrogativa da federação, tornaram-se atribuições do governo estadual. Este crescimento no número de municípios esteve diretamente relacionado às mudanças na legislação, em decorrência do aumento dos repasses para esses entes federativos. Salienta-se que, apesar do incremento das transferências, observou-se a existência de vários municípios que praticamente não dispunham de receitas próprias.

\section{O ESPAÇO DO PODER LOCAL PRÉ-CONSTITUIÇÃO}

Uma das alterações ocorridas ao longo da ditadura militar (1964-1985) foi a redução da autonomia dos municípios em relação à tomada de decisão política.

Esse processo fica bem evidenciado na reforma tributária de 1966. Com essa alteração jurídica foram estabelecidos níveis de competência de arrecadação. Porém, grande parcela dos recursos destinados às localidades era originária de transferências da União e estados, além de recursos de natureza parafiscal.

Em razão da natureza do regime, parte das transferências realizadas não seguia critérios claros de institucionalidade. Basicamente, eram determinadas em função de planejamento em âmbito nacional ou, na maioria das vezes, seguindo ditames de favorecimento a aliados políticos.

Assim, uma das marcas do golpe foi o processo centralizador, trazendo um quadro enorme de dificuldades para as unidades locais de poder.

As mudanças desse período, no que diz respeito às relações entre os entes federativos, podem ser apresentadas em dois eixos: processo de concentração e controle das ações, no tocante a políticas públicas por parte do poder central e centralização dos recursos orçamentários como instrumento de política econômica, principalmente com a preocupação de redução do déficit orçamentário. Desse modo, uma série de alterações ocorreu no âmbito da legislação, e mesmo o limitado grau de autonomia das localidades desapareceu.

Ressalta-se que, entre outros aspectos, o modelo econômico vigente promoveu um forte quadro de 
concentração de renda. De acordo com Mello (1998), há nesse período a privatização da esfera pública com o crescimento da participação dos tecnocratas no governo, favorecendo grandes grupos econômicos.

Acerca da matéria tributária, percebeu-se uma concentração com a visível redução da participação dos governos estaduais e municipais no bolo orçamentário. Além disso, um conjunto significativo de transferências ocorridas da União para as localidades caracterizou-se por atos discricionários. Dessa maneira, localidades com mandatários vinculados ao partido da oposição enfrentavam maiores dificuldades com relação aos repasses.

A partir de 1968, surgem alterações no tocante às transferências de recursos para estados e municípios, como por exemplo, a criação do Fundo de Participação dos Municípios (FPM). De acordo com essa legislação, $10 \%$ dos recursos arrecadados da União com os Imposto de Renda (IR) e com o Imposto sobre Produtos Industrializados (IPI) teriam como destino o FPM. Desse montante, $10 \%$ seriam destinados às capitais e $90 \%$ para os demais municípios. No entanto, já em 1969, ocorre uma redução na receita do IR e do IPI, que seriam destinados aos estados e municípios. Também, como observa Prado (1994), ao longo dos anos 1970, o Brasil foi um exemplo único de redução de carga tributária diante de uma situação de crise.

Com a implantação do II Plano Nacional de Desenvolvimento (II PND), a partir de 1974, tendo como estratégia desenvolver a produção dos bens de consumo duráveis, o governo recorreu de modo bastante agressivo aos mecanismos de isenção tributária. Além disso, ocorria a utilização de isenção fiscal como elemento de combate à inflação.

Desse modo, a utilização desse mecanismo, incidindo principalmente sobre o IPI e o Imposto sobre Circulação de Mercadorias (ICM), provocou um impacto significativo sobre as finanças dos estados e municípios. Esse fato fez que ao longo do período se observasse uma queda na participação dos estados e municípios na receita tributária total.

Em 1967 cabia à União 36\% das receitas, aos estados 46\% e aos municípios 17,6\%. Em 1974 a participação da União se apropriava de 50,5\% da receita tributária total, os estados ficavam com $36 \%$ e os municípios com 13,5\% (BOVO, 2000).

Apesar da reforma de 1966, e a consequente institucionalização das transferências, a despeito do crescimento econômico, as finanças públicas locais, e, por decorrência, a capacidade de intervenção nas políticas públicas sofreram enormes constrangimentos. Contribuiu sobremaneira para esse processo o conjunto de isenções fiscais ocorridas ao longo do período em questão.

\section{As MUdAnÇAs A PARTIR DA CONSTituição DE 1988}

A transição democrática ocorrida no Brasil apresentou como elemento síntese pressões no sentido da descentralização das esferas de poder, principalmente em benefício das localidades.

Apesar de ser uma bandeira dos movimentos sociais organizados e dos partidos de esquerda, observa-se na literatura econômica que, paulatinamente, os grupos conservadores também se apropriaram da causa em prol da descentralização.

Enquanto para os movimentos sociais, o processo de descentralização significava a possibilidade de maior controle social pelos cidadãos, justiça social, redução das desigualdades e, consequentemente, maior alcance das políticas públicas, na perspectiva do conservadorismo, a descentralização tinha como objetivo imprimir uma maior racionalidade nas ações do Estado.

Essa leitura da descentralização passou a integrar as políticas e recomendações dos organismos multilaterais para países da América Latina egressos de regimes autoritários. Talvez esse deva ser um dos aspectos que explique a facilidade com que o processo de reformas do Estado ao longo dos anos 1990 fosse realizado na América Latina sem oferecer grandes resistências.

Importante destacar que esse processo aconteceu mesmo antes da promulgação da Constituição de 1988. A força dos movimentos populares, aliada à crise econômica dos anos 1980, fez que a União enfrentasse dificuldades na manutenção desse arranjo institucional. Nos principais centros urbanos emergiram inúmeros movimentos organizados em torno de reivindicações sociais de várias naturezas, principalmente de saúde e moradia.

No processo constituinte, esse conjunto de demandas sociais passa a integrar a pauta de discussões. Desse modo, as lutas para democratização do país se confundem, em grande medida, com descentralização de poder político.

Nesse momento ocorre um paradoxo no sistema político brasileiro, na medida que a descentralização surge como uma necessidade a ser defendida pelos movimentos sociais organizados e também pelas correntes políticas conservadoras, cada qual dentro de uma perspectiva distinta. 
Dessa maneira, inicia-se uma luta política no Parlamento em torno da instituição de mecanismos que possibilitassem o aumento da presença do poder local bem como da influência da população organizada. Como já destacado, a origem da luta em favor da descentralização no país decorre da identificação do modelo centralizador com autoritarismo político.

Assim, a Constituição de 1988 coloca na agenda política do país o debate acerca da redemocratização e da descentralização.

Durante as discussões em torno da definição da estrutura tributária bem como o padrão de gasto social do Estado, um número significativo de demandas reprimidas ao longo da ditadura militar emergiu.

No âmbito das relações entre os entes federativos assume extrema importância a reforma tributária realizada na Constituição de 1988. Essa apresentou como principal virtude a institucionalização das transferências e o estabelecimento de critérios técnicos na participação dos fundos para-fiscais. Como resultado, percebe-se a partir do ano de 1988, gradativa redução na renda disponível em poder da União e o aumento da participação dos municípios como pode ser observado no Gráfico 1.
Em contrapartida, estabeleceu-se um aumento das responsabilidades das esferas locais de poder na gestão das políticas públicas. A criação do Sistema Único de Saúde (SUS) impôs a necessidade da gestão e prestação dos serviços em âmbito local e, no caso da educação fundamental, o município teve a parcela de seus recursos vinculados.

Afonso (2001) destaca que uma importante característica da reforma estabelecida na Constituição de 1988 foi o processo de municipalização, redundando em grande autonomia tributária de entes federativos. Como desdobramento deste processo, principalmente em grandes cidades, o quadro de aumento da receita própria decorre também da modernização fazendária e melhoria nos sistemas de avaliação das propriedades imobiliárias, bem como o crescimento dos serviços frente à indústria e comércio.

Assim, as grandes cidades, apesar de menor participação no FPM, dispõem de ferramentas mais sofisticadas, que possibilitam ampliar sua capacidade de arrecadação, além do próprio dinamismo da economia que favorece aumento da arrecadação tributária. Desse modo, acredita-se que a melhoria da gestão e dos sistemas de controle pode aumentar as receitas oriundas de arrecadação própria.

Gráfico 1. Receita disponível por nível de governo.

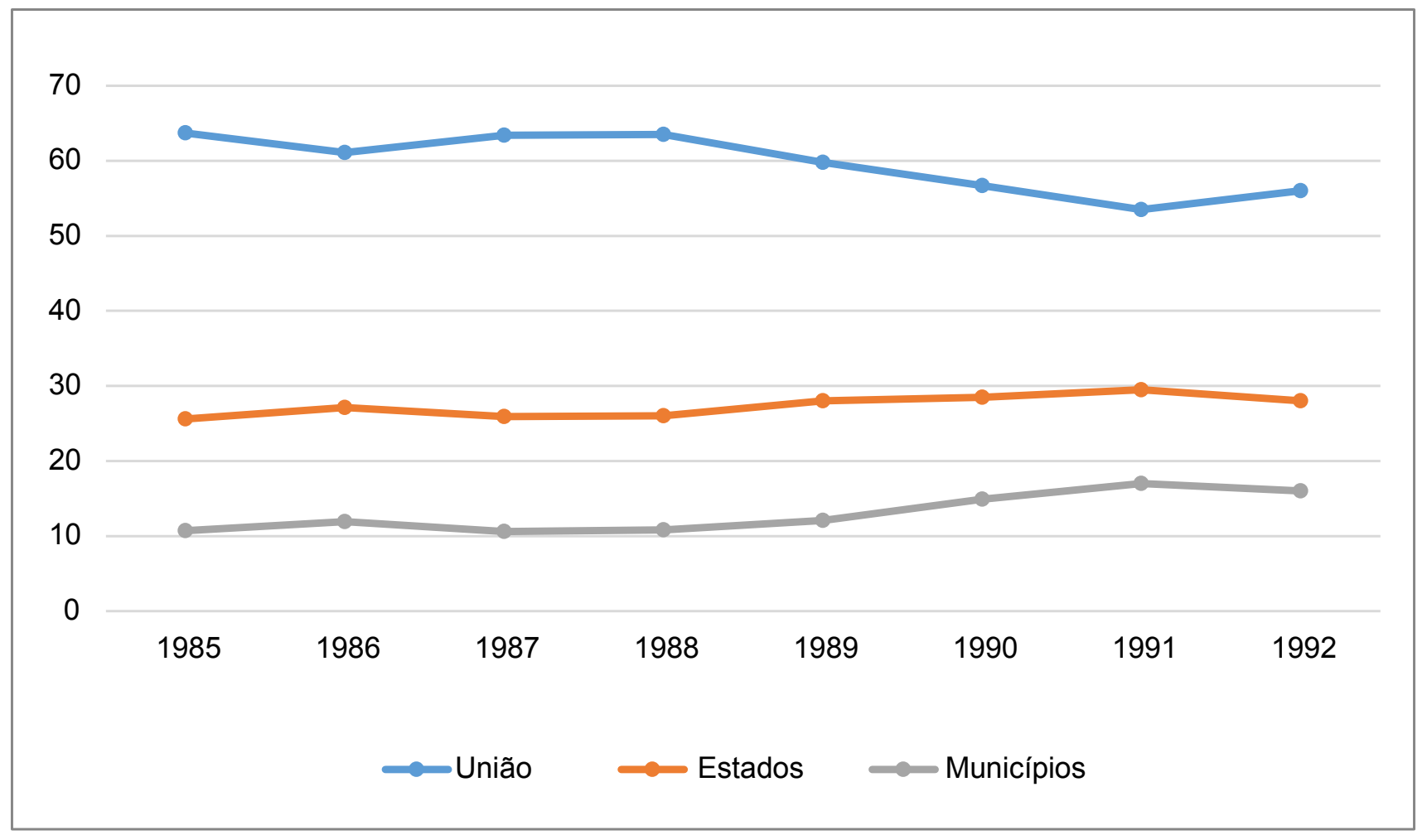

Fonte: Instituto de Pesquisas Econômicas Aplicadas (2017). 
Ainda em relação às características da estrutura fiscal brasileira, Prado (1994) observa a ausência de orientação para o processo de adequação dos mecanismos de financiamento federativo. Seu principal argumento é que, "inexiste ou é limitado o espaço político para qualquer alteração no regime de competências".

Analisando o sistema de transferências constitucionais, observa-se que esse modelo tende a privilegiar as capitais, na medida em que estas possuem 22,8\% da população, e auferem 33,2\% dos recursos disponíveis, enquanto $3 \%$ dos residentes nos municípios abaixo de 5.000 recebem 3,6\% dos recursos. Na distribuição dos recursos de modo que, a não existência provocaria concentração em prol das capitais.

Desse modo, o debate em torno do processo de descentralização abre duas vertentes: a necessidade de descentralização do processo decisório em favor dos estados e municípios e a possibilidade de incremento nos recursos tributários à disposição das localidades. No tocante às alterações ocorridas no âmbito da tributação, percebe-se a gradativa redução na renda disponível em poder da União e significativo aumento da participação dos municípios. De acordo com a Tabela 1, em 1985 a União detinha $63,70 \%$ do total da receita disponível nas três esferas de governo, e em 1992 ocorre uma redução para $56 \%$, ao passo que no caso dos municípios, durante o mesmo período ocorre um aumento de $10,7 \%$ para $17 \%$.
Do mesmo modo em que houve uma redução na participação da União na apropriação das receitas orçamentárias, também foi muito enfatizada pela literatura a sensível redução da presença do governo federal no gasto social, com pressões principalmente sobre os municípios, fato que, como já destacado, ocorreu antes inclusive da promulgação da Constituição de 1988.

\section{A CRISE RECENTE E AS NOVAS ESTRATÉ- GIAS DE GESTÃO MUNICIPAL}

Ao longo dos últimos trimestres, a economia brasileira apresentou intenso quadro de desaceleração. A trajetória do comportamento do PIB do país pode ser acompanhada por meio do Sistema de Contas Nacionais Trimestrais.

Essa pesquisa disponibiliza trimestralmente índices que possibilitam acompanhar a evolução do PIB e de seus principais componentes.

O primeiro trimestre de 2014 foi o derradeiro, com indicadores positivos em todos os setores de atividade econômica. A partir do segundo trimestre, houve uma progressiva queda no PIB e seus componentes. Apenas a atividade agropecuária apresentou indicadores positivos em alguns dos trimestres analisados, como pode ser observado no Gráfico 2.

Gráfico 2. Variação do PIB em volume em relação ao mesmo trimestre do ano anterior (\%).

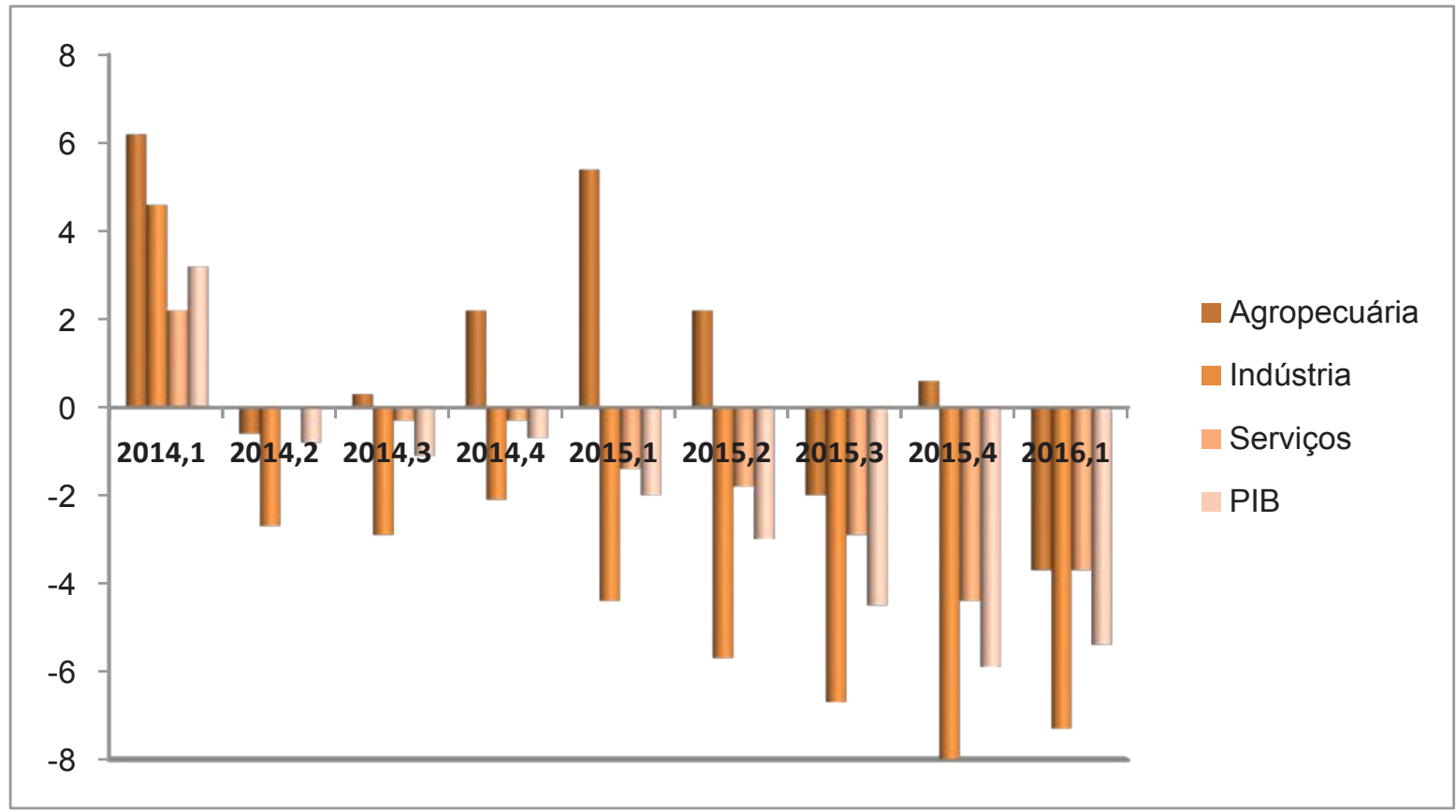

Fonte: Instituto Brasileiro de Geografia e Estatística (2017). 
Esses índices dizem respeito ao conjunto da economia brasileira, porém, estados e municípios também sofreram impactos negativos com o quadro de retração da produção e de emprego ao longo do período.

Muitos municípios brasileiros passaram a adotar os instrumentos políticos, dentro de sua esfera de autonomia. As utilizações de mecanismos de incentivo à implantação de investimentos podem inclusive ter contribuído para atenuar a retração no nível de emprego.

Além disso, os municípios recorreram também à política de isenção de taxas e de IPTU, o principal tributo de competência dessa esfera de governo.

Assim como ocorreu em âmbito federal, no nível municipal também foram utilizados instrumentos que podem ser traduzidos como renúncia fiscal.

De acordo com o Gráfico 3, é possível perceber que ocorreu um aumento no uso desses mecanismos de incentivo à atividade econômica. Por exemplo: Do total de municípios brasileiros, em 2015, 42,8\% promoviam a cessão de terrenos, com intuito de atrair novos investimentos. Em 2012, a taxa era correspondente a $38,5 \%$. Além disso, os municípios recorreram também aos mecanismos de isenção de taxas e de IPTU, o principal tributo de competência dessa esfera de governo.

No estado de São Paulo, também foi grande a ocorrência de municípios que utilizaram mecanismos de incentivo à implantação de investimentos. Em 410 municípios paulistas observou-se a utilização desses mecanismos, enquanto em âmbito nacional a maior frequência foi a modalidade cessão de terrenos. No caso dos municípios paulistas, a isenção do IPTU apresenta maior relevância, como pode ser observado no Gráfico 4.

Considerando apenas a existência desses mecanismos nos municípios paulistas, essa taxa chega a $63,5 \%$. Há diferenças importantes quando se realiza a estratificação de acordo com o porte populacional dos municípios.

Nesse caso, é importante destacar que $42 \%$ das cidades paulistas possuem menos de 10 mil habitantes, em contrapartida, em 2015, apenas 9 possuíam população superior a 500 mil habitantes. Desse último grupo, apenas dois, Santo André e São Bernardo do Campo, não adotavam instrumentos de incentivo à implantação de investimentos.

A ocorrência mais elevada estava no grupo de municípios de médio porte, entre 50.001 e 100.000 habitantes, com uma presença de $88,3 \%$.

Outra estratégia de gestão amplamente utilizada pelos municípios foi a terceirização. É verdade que esse processo foi menos intenso, uma vez que o ápice ocorreu após a implantação do Plano Real, com a imposição para que os municípios contribuíssem com o esforço de ajuste fiscal.

As terceirizações estiveram presentes em um número significativo de municípios do estado de São Paulo, especialmente no caso de atividades relacionadas à infraestrutura urbana. Em algumas atividades, investigadas na Pesquisa de Informações Básicas Municipais, é possível notar a ocorrência de processo mais intenso nos municípios maiores em termos populacionais.

Gráfico 3. Municípios no Brasil com incentivo a implantação de investimentos (\%).

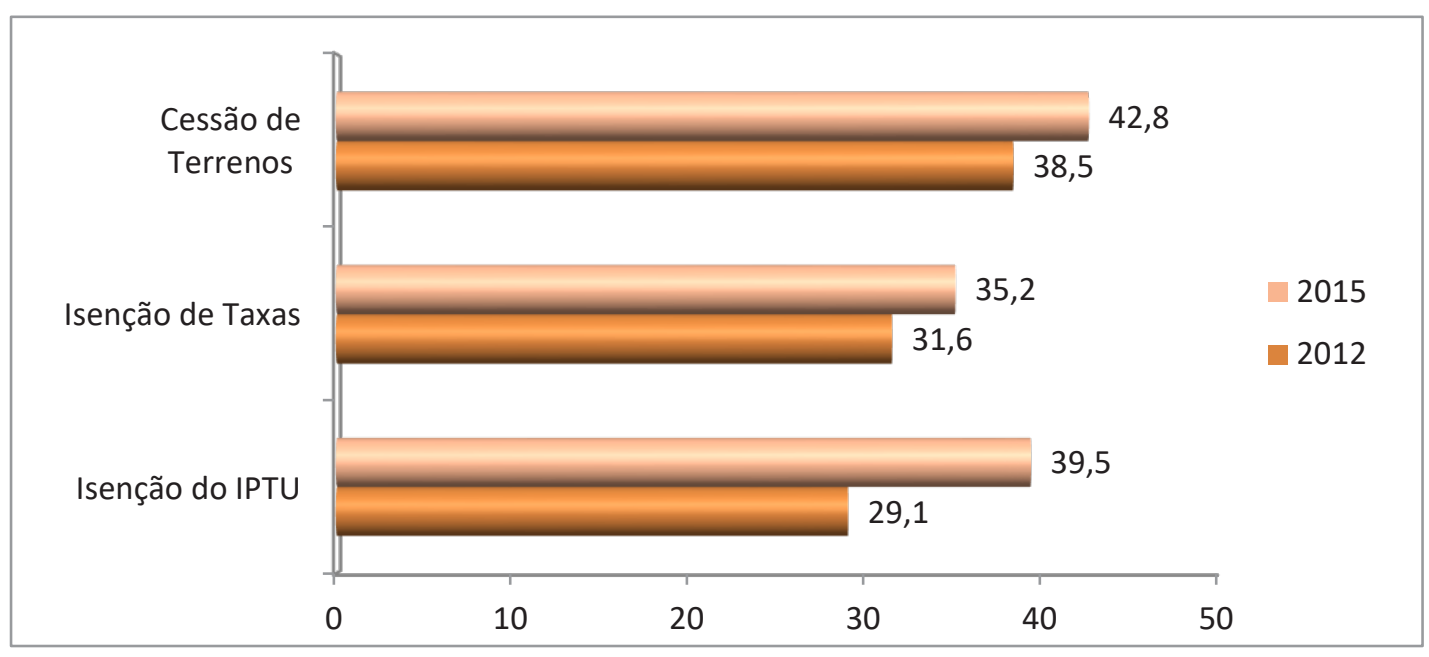

Fonte: Instituto Brasileiro de Geografia e Estatística (2015). 
Gráfico 4. Municípios com incentivo à implantação de investimentos no estado de São Paulo.

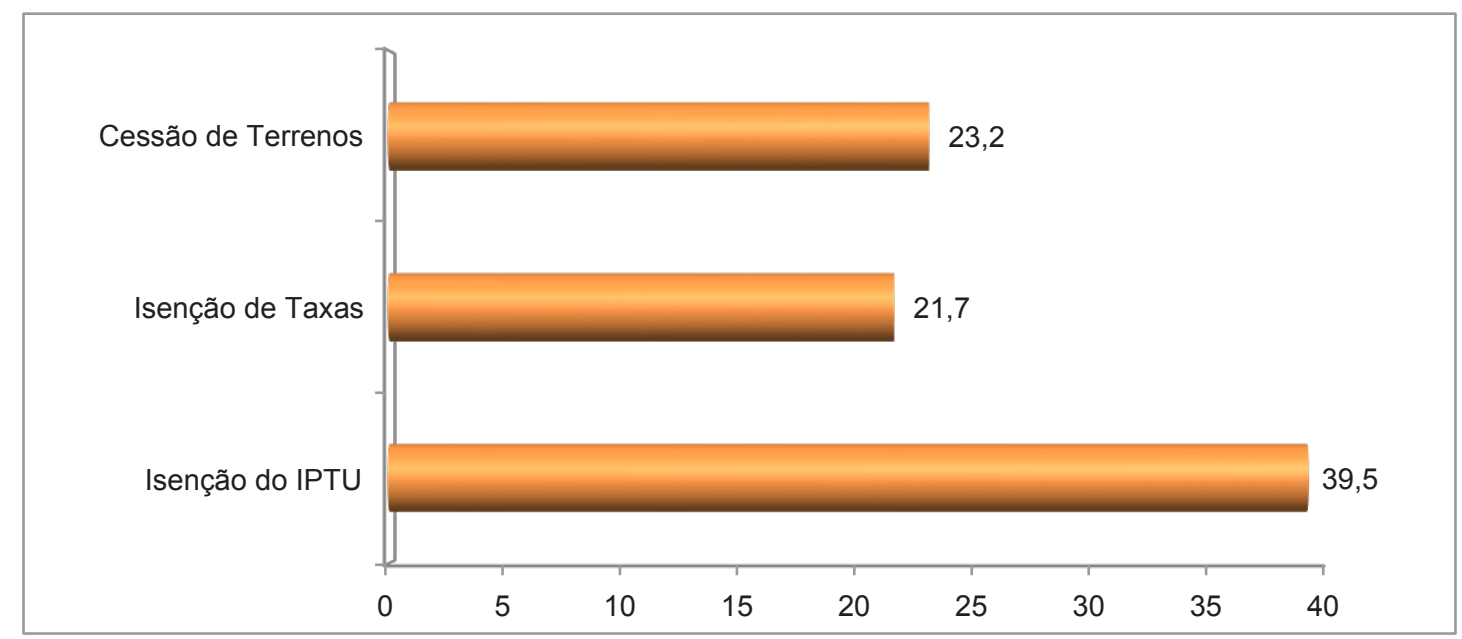

Fonte: Instituto Brasileiro de Geografia e Estatística (2015).

Gráfico 5. Municípios com incentivo à implantação de investimentos no estado de São Paulo, de acordo com o tamanho da população.

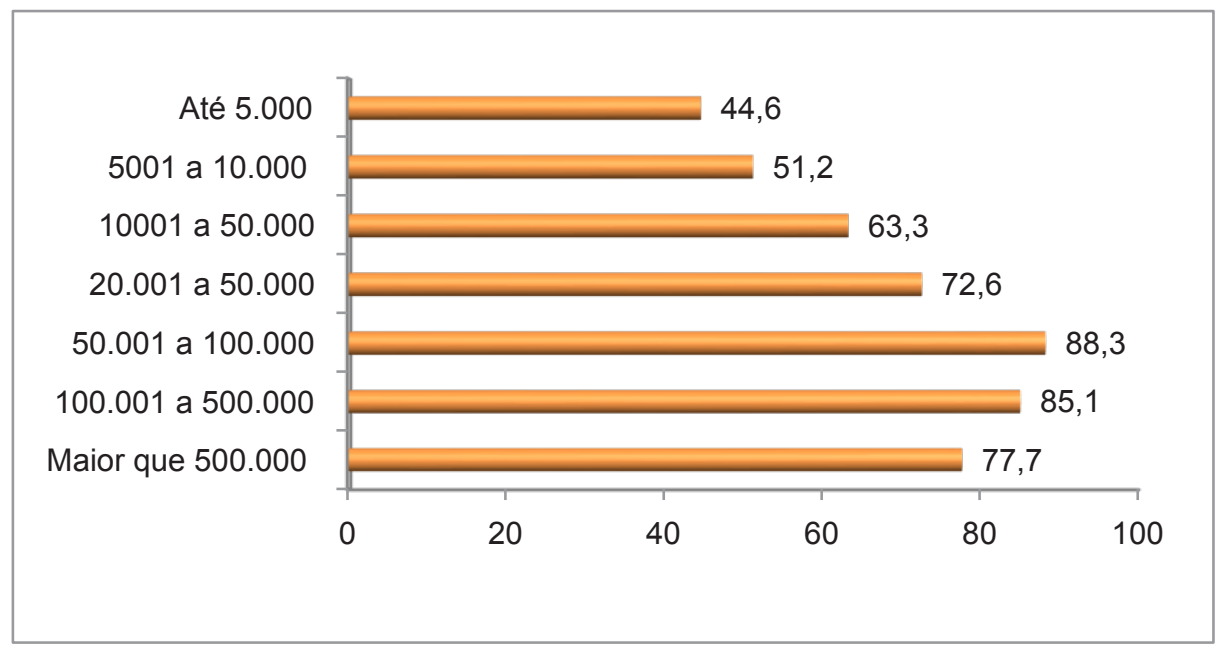

Fonte: Instituto Brasileiro de Geografia e Estatística (2015).

As atividades relacionadas à infraestrutura urbana foram paulatinamente alvos de processos de terceirização em um número significativo de municípios. Apesar das discussões em torno da reforma do Estado na esfera nacional ter como premissa um possível aumento na racionalidade e eficiência da máquina, como já destaca Bresser-Pereira (1998), em âmbito local acredita-se que tal processo passe ao largo desse debate.

Novamente, o que se observa é um movimento de reação às restrições que se apresentam às localidades. A Tabela 1 apresenta o comportamento desse processo no ano de 2015.
Nas tabelas é possível observar que dos $645 \mathrm{mu}-$ nicípios do estado de São Paulo, aproximadamente $33 \%$ terceirizaram a coleta de lixo residencial, e $30 \%$ a limpeza urbana. Em comparação com o ano de 2001, fica evidente o aumento da terceirização nesses setores. Em relação à participação da atividade terceirizada nos serviços de advocacia e de contabilidade, não houve grandes alterações, sendo respectivamente $44 \%$ e $32 \%$. O agravante é que o total de atividade terceirizadas é de quase $91 \%$, ou seja, dos 645 municípios, cerca de 586 tem atividades terceirizadas. 
Tabela 1. Municípios com atividades terceirizadas no Brasil e no estado de São Paulo em 2015.

\begin{tabular}{lcccc}
\hline \multirow{2}{*}{ Atividades terceirizadas } & \multicolumn{2}{c}{ Municípios } & \multicolumn{2}{c}{ Em percentual } \\
\cline { 2 - 5 } & Brasil & São Paulo & Brasil & São Paulo \\
\hline Assessoria jurídica & 842 & 289 & 15.12 & 44.81 \\
Assessoria contábil/financeira & 605 & 375 & 10.86 & 58.14 \\
Coleta de resíduo sólido domiciliar & 2164 & 217 & 38.85 & 33.64 \\
Coleta de resíduo sólido hospitalar & 4796 & 526 & 86.10 & 81.55 \\
Limpeza urbana & 356 & 198 & 6.39 & 30.70 \\
Iluminação pública & 2008 & 215 & 36.05 & 33.33 \\
\hline
\end{tabular}

Fonte: Instituto Brasileiro de Geografia e Estatística (ANO).

\section{Os IMPACTOS DAS MEDIDAS SOBRE O NÍVEL DE EMPREGO}

Ainda não é possível avaliar os impactos diretos dessas medidas sobre a capacidade de recuperação da atividade econômica dos municípios. As estatísticas relativas às estimativas do PIB municipal, elaboradas pelo IBGE, estão disponíveis apenas até o ano de 2013. De qualquer modo, a retração da atividade econômica no biênio 2014/2015 trouxe impactos negativos para praticamente todos os municípios brasileiros.

Em relação às estatísticas relativas ao mercado de trabalho, pelo menos até o início de 2015, havia restrições em razão da restrita cobertura das taxas de desocupação ${ }^{1}$.

A partir de março de 2015 ocorre a substituição da PME pela Pesquisa Nacional por Amostra de Domicílios Contínua. Esse novo levantamento passou a caracterizar o mercado de trabalho brasileiro em todas as unidades da federação e capitais. Desse modo, é possível observar o comportamento das taxas de desocupação em todas as capitais do país.

Tabela 2. Taxa de desocupação das capitais em 2014/2016 (\%).

\begin{tabular}{lcc}
\hline \multirow{2}{*}{ Municípios } & \multicolumn{2}{c}{ Taxa de Desocupação } \\
\cline { 2 - 3 } & $\begin{array}{ccc}\text { abril-junho } \\
\mathbf{2 0 1 4}\end{array}$ & $\begin{array}{c}\text { abril-junho } \\
\mathbf{2 0 1 6}\end{array}$ \\
\hline Porto Velho & 4,1 & 10,2 \\
Rio Branco & 12,6 & 13,2 \\
Manaus & 10,2 & 17,4 \\
\hline
\end{tabular}

(continua)

1 A taxa de desocupação calculada pelo IBGE era obtida por meio da Pesquisa Mensal de Emprego e considerava a soma das taxas de seis regiões metropolitanas (Recife, Salvador, Belo Horizonte, Rio de Janeiro, São Paulo e Porto Alegre)
Tabela 2. Continuação

\begin{tabular}{lcc}
\hline \multirow{2}{*}{ Municípios } & \multicolumn{2}{c}{ Taxa de Desocupação } \\
\cline { 2 - 3 } & $\begin{array}{c}\text { abril-junho } \\
\mathbf{2 0 1 4}\end{array}$ & $\begin{array}{c}\text { abril-junho } \\
\mathbf{2 0 1 6}\end{array}$ \\
\hline Boa Vista & 5,6 & 8,7 \\
Belém & 11,2 & 13,2 \\
Macapá & 10,2 & 17,4 \\
Palmas & 10,9 & 10,0 \\
São Luís & 8,6 & 16,4 \\
Teresina & 8,0 & 9,6 \\
Fortaleza & 7,5 & 11,4 \\
Natal & 10,7 & 13,7 \\
João Pessoa & 10,6 & 10,8 \\
Recife & 7,5 & 11,6 \\
Maceió & 10,5 & 13,8 \\
Aracaju & 10,5 & 16,1 \\
Salvador & 12,8 & 17,6 \\
Belo Horizonte & 6,4 & 12,0 \\
Vitória & 8,1 & 11,0 \\
Rio de Janeiro & 5,2 & 7,3 \\
São Paulo & 6,6 & 10,6 \\
Curitiba & 3,6 & 10,2 \\
Florianópolis & 4,0 & 7,2 \\
Porto Alegre & 4,0 & 8,7 \\
Campo Grande & 3,9 & 7,2 \\
Cuiabá & 5,3 & 13,4 \\
Goiânia & 3,3 & 7,7 \\
Brasília & 9,2 & 10,9 \\
\hline
\end{tabular}

Fonte: Instituto Brasileiro de Geografia e Estatística (2016).

Na comparação entre o segundo trimestre de 2014 e o de 2016, é possível observar que ocorreu um aumento expressivo nos indicadores de desocupação praticamente em todas as capitais do país. Salvador, Manaus e Macapá apresentam taxas extremamente elevadas: 17,6; 17,4 e 17,4 respectivamente.

Paralelamente, nesse grupo de municípios a maior parcela lançou mão de instrumentos designados como políticas de emprego e geração de renda. Do conjunto 
de capitais, 64\% implantaram uma política de isenção de Imposto Territorial Urbano em 2002, e em 2005 o número sobe para 75\%. No caso do Imposto sobre Serviços, 64\% dos municípios adotaram esse tipo de política de "geração de emprego e renda".

Ou seja, a permanência da utilização da desoneração tributária implementada pelas localidades não foi capaz de atenuar a crise no mercado de trabalho, iniciada no fim de 2014. Significa dizer que o alcance do município é limitado, no tocante ao enfrentamento de uma crise da dimensão pela qual a economia brasileira enfrentou. Desse modo, as desonerações impactaram na redução da receita dos municípios e na capacidade de atender políticas públicas no âmbito local.

Gráfico 6. Percentual de capitais que promoveram isenção por modalidade de tributos.

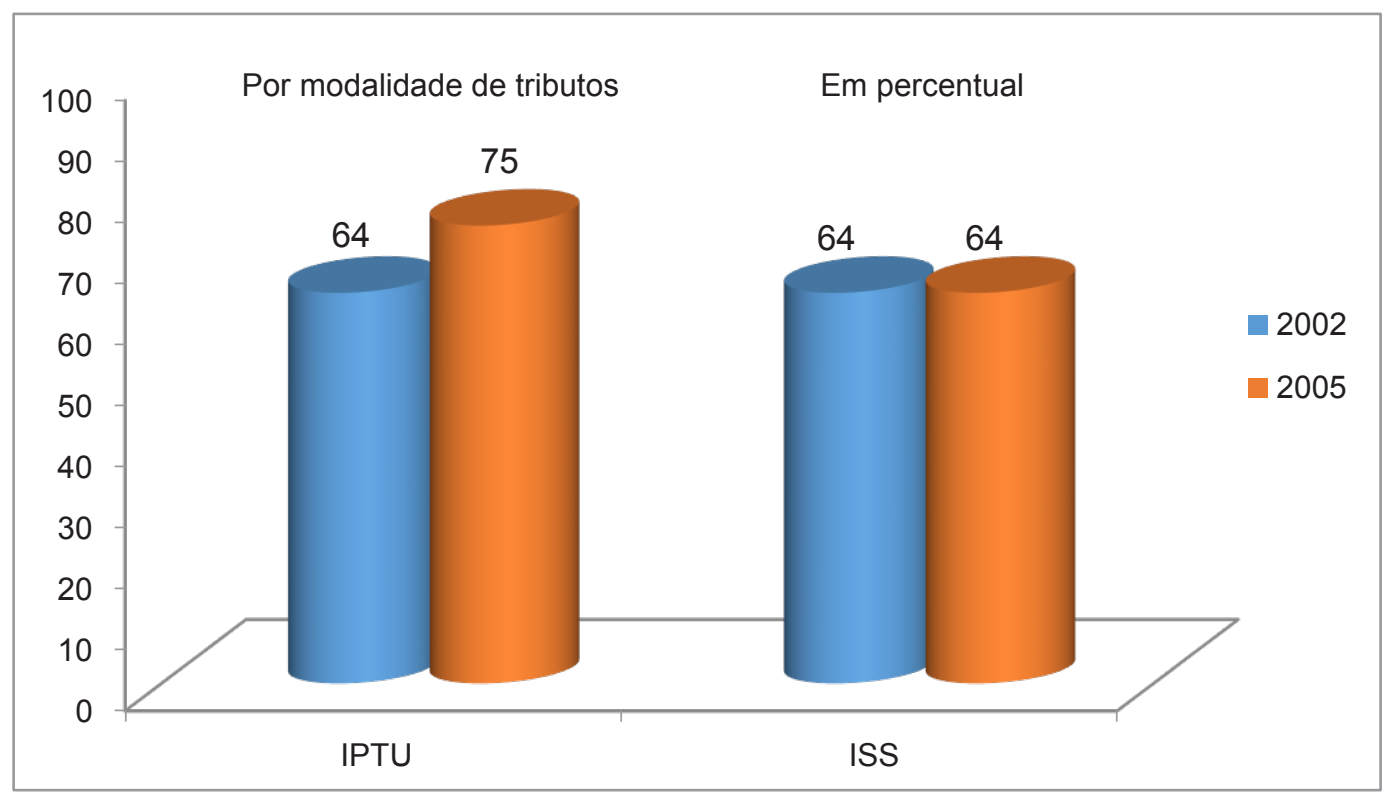

Fonte: Instituto Brasileiro de Geografia e Estatística (ANO).

\section{CONSIDERAÇÕES FINAIS}

Este trabalho pretendeu observar que algumas estratégias utilizadas pelo governo federal no enfrentamento da crise, especialmente pós 2014, também foram adotadas amplamente em nível municipal. Foi possível observar que um grande número de cidades do país vem adotando sistematicamente estratégias de desoneração tributária, com intuito de reverter o ciclo econômico. Inclusive, algumas cidades denominam esse processo como estratégia de geração de emprego e renda.

Assim, foi possível observar que os municípios brasileiros recorreram aos instrumentos de incentivo à implantação de investimentos como resposta a um quadro de retração da atividade econômica. A pesquisa demonstrou que houve ao longo dos últimos trimestres um intenso quadro de desaceleração no PIB brasileiro. No caso do estado de São Paulo, nas cidades de médio e grande porte, houve a utilização com maior frequência desse mecanismo. Nos municípios de menor porte, apesar de menos frequente, foi bastante significativo o uso dessas modalidades de incentivo à atividade econômica.

Entre as capitais também houve expressiva utilização desses mecanismos.

Outro aspecto deste estudo evidencia que a terceirização é uma estratégia de gestão amplamente utilizada pelos municípios, e suas variações ocorrem de acordo com os termos populacionais. Ou seja, além da desoneração tributária, a redução do alcance e atuação do poder público foi a alternativa utilizada pelos municípios para sair da crise.

Por fim, a despeito da utilização das estratégias observadas, as taxas de desocupação não cederam e, a partir do final de 2015, assumem patamares extremamente elevados em três capitais: Manaus, Salvador e Macapá. 


\section{REFERÊNCIAS}

AFONSO, J. R. R.; ARAÚJO, E. A. A capacidade de gasto dos municípios brasileiros: arrecadação própria e receita disponível. Brasília, DF: BNDES, 2001. Disponível em: <https://goo.gl/UirngQ> Acesso em: 22 jun. 2017.

BRASIL. Constituição (1988). Constituição da República Federativa do Brasil. Promulgada em 5 de outubro de 1988. Brasília, DF, 1988. Disponível em: <https://goo. gl/cbu8fh>. Acesso em: 07 jul. 2017.

BRESSER-PEREIRA, L. C. A reforma do Estado nos anos 90: lógica e mecanismos de controle. Lua Nova, São Paulo, n. 45, p. 49-95, 1998.

BOVO, J. M. Federalismo fiscal e descentralização de políticas públicas no Brasil. São Paulo: Unesp, 2000.

INSTITUTO BRASILEIRO DE GEOGRAFIA E ESTATÍSTICA. Contas nacionais. Rio de Janeiro: IBGE, 2017. Disponível em: <https://goo.gl/aQmD$\mathrm{Kg}>$. Acesso em: 12 jul. 2017.
Pesquisa de informações básicas municipais (2001-2015). Rio de Janeiro: IBGE, 2015.

INSTITUTO DE PESQUISAS ECONÔMICAS APLICADAS. Receita disponível por nível de governo. Disponível em: <https://goo.gl/xEAhEa>. Acesso em: 12 jul. 2017.

MELLO, J. M. G.; NOVAIS, F. A. O capitalismo tardio e a sociabilidade moderna. In: NOVAIS, F. A. (Coord.). História da vida privada no Brasil: contrastes da intimidade contemporânea. São Paulo: Companhia das Letras, 1998. v. 4, p. 559-658.

PRADO, S. R. R. Intervenção estatal, privatização e fiscalidade: um estudo sobre a constituição e crise do setor produtivo estatal no Brasil e os processos de privatização a nível mundial. 1994. 316 f. Tese (Doutorado em Economia) - Instituto de Economia, Universidade Estadual de Campinas, 1994.

TAVARES, M. C; ASSIS, J. C. O grande salto para o caos. 2. ed. Rio de Janeiro: Jorge Zahar, 1986. 